\title{
Prediction of the Physico-Chemical Interactions of Vimtim Stream Water Quality using the Aquatox Model
}

\author{
Anyadike, C. C. ${ }^{1}$, Mbajiorgu, C.C. ${ }^{1}$, and Ajah, G.N. ${ }^{2}$ \\ ${ }^{1}$ Department of Agricultural and Bioresources Engineering University of Nigeria, Nsukka. \\ ${ }^{2}$ Department of Electrical Engineering University of Nigeria, Nsukka.
}

\begin{abstract}
Hydrological and chemical data of water bodies are very scarce and the available ones are sparse in Nigeria compared to other developed countries. AQUATOX model was used in this study to simulate physicochemical interactions of water quality parameters in Vimtim stream, Mubi, Adamawa State, Nigeria. Three months data were input into AQUATOX model for its calibration after which the model was applied for an extended period of one year. The model was used to predict the behavior and interactions of some biotic and abiotic variables. The model output result agreed with observed result, which stated that the water quality parameters monitored were within the acceptable standard. However the one year model prediction recorded a reduction in catfish production
\end{abstract}

Keywords: - AQUATOX, Modeling, Stream Water Qaulity

\section{INTRODUCTION}

The increasing worldwide contamination of freshwater systems with thousands of industrial, agricultural and natural chemical compounds is one of the key environmental problems facing humanity. Although most of these compounds are present at low concentrations, many of them raise considerable toxicological concerns, particularly when present as components of complex mixtures. Human inclusions in the ecosystem by means of wastewater treatment effluents and/or agricultural/fertilization practices are typical causes for the imbalance of nutrients in the ecosystem. Aquatic environment, as a significant and constituent part of the whole environment system, receives majority of these pollutants. Hazardous substances released into the aquatic environment are transported and distributed in complex aquatic environmental components. Effective environmental management practices for pollution accidents are dependent on the clear understanding of the environmental fate and ecological risk of chemicals [1]. The conventional methods and technologies for assessing the environmental fate and ecological risk of chemicals are mainly dependent on chemical analysis and biological toxicity tests, such as, instrumental detection, single species toxicity tests, multiple-species toxicity tests, and mesocosm tests [2]. Conventional methods have their inherent virtues such as precision and credibility, however, performing a large number of these experiments may be inappropriate, because these tests are laborious, expensive, and time consuming [3]. In contrast to the high cost for multimedia monitoring and toxicity tests, and the need for rapid forecasting analysis, a comprehensive aquatic ecological system model would be cost-effective, fast, and a suitable evaluation tool [4,3]. An ecological model, which can be defined as a simplified representation of a specific ecological system, may be the only option for assessing chemical effects under circumstances where field experiments cannot be conducted [5].

Some reviews concerning the use of ecological models in ecological risk assessment have been published [610]. Among these models, AQUATOX, developed by Park et al. [11], is one of the relatively few comprehensive models that have been designed specifically for environmental behaviors and the ecological impact assessment of pollutants.

Most of Nigeria's water bodies receive pollutants indiscriminately discharged by industries, runoff laden with pesticides, inorganic and organic fertilizers used in farming. These pollutants even at low concentrations may present high risks to the environment. Hence, it is necessary to assess the environmental fate and aquatic ecological risk of pollutant released into our water bodies by using a simple and effective evaluation tool for environment management. Conventional measurement has been used in assessing the physio-chemical interactions of Vimtim stream in Mubi, Adamawa State [12], but the study was for a period of three months. David et al [12] reported that the water quality parameter of the river were within the recommended standard [13] and favourable to fish production. However, this was done for a short period and the interaction of other aquatic variables was not considered. This study, therefore, aimed at validating the comprehensive aquatic ecological system model; AQUATOX using David et al [12] field result. 


\section{METHODOLOGY}

Historical data of a study carried out on the water quality condition of Vimtim (Gramta) stream located in Mubi North Local Government Area, in Adamawa State by David et al. [12] was used to validate the AQUATOX model. Mubi North has Coordinates: $10^{\circ} 16^{\prime} \mathrm{N} 13^{\circ} 16^{\prime} \mathrm{E} / 10.267^{\circ} \mathrm{N} 13.267^{\circ} \mathrm{E}$ [14], wind $1.67 \mathrm{~ms}-1$, Elevation: $1867 \mathrm{ft}$. The source of the Vimtim stream is from two mountains located in southern and eastern part of the community. The stream serves many purposes which include, fishing (the main occupation of the indigenes), source of irrigation for the surrounding farmlands as well as a source of drinking water for humans and animals, especially cattle. A number of miscellaneous water users also participate in this value chain. Many depend on the resources of this water as their main sources of food and family income as a result the water is subjected to intensive use [12].

\subsection{The model}

The AQUATOX model is a comprehensive aquatic ecosystem model that predict the environmental fate and effects of conventional pollutants such as nutrients and toxic chemicals in aquatic ecosystems. The chemical fate portion of the AQUATOX predicts the partitioning of a chemical into water, sediment, particulate, and biota. Microbial degradation, biotransformation, photolysis, hydrolysis, and volatilization are also modeled implicitly in the AQUATOX. The effects portion of the model includes a direct toxic-effect that is used to extrapolate the potential effects of chemicals on the biomass production in an aquatic ecosystem from acute and chronic toxicity data (LC50 or EC50) of single-species to the various organisms modeled, indirect effects such as an increase in detritus and recycling of nutrients from organisms that have been killed, and dissolved oxygen sag because of increased decomposition. The AQUATOX represents the aquatic ecosystem by simulating timedependent concentrations of organisms, nutrients, and chemicals in a unit volume of water [15].

The input data used to execute AQUATOX 3.1 is as shown in Table 1. The data include site characteristics, mean nutrient mass loadings and concentrations. The relevant physiological parameters used in the model are from the original AQUATOX model, and from the biological and ecological literature.

Table 1: Input Data usedin initializing the AQUATOX model

\begin{tabular}{|l|l|l|}
\hline Variable & Source & Format \\
\hline Site characteristics & $\begin{array}{l}\text { Google Earth 2011, } \\
\text { http://en.wikipedia.org/wiki/ } \\
\text { Mubi_North }\end{array}$ & $\begin{array}{l}\text { Length, depth, volume of stream (assumed), latitude } \\
\text { and longitude, elevation. }\end{array}$ \\
\hline Temperature & David et al [12] & $\begin{array}{l}\text { Monthly mean temperature from June - September, } \\
2009\end{array}$ \\
\hline pH & David et al [12] & Monthly mean pH from June - September, 2009 \\
\hline Turbidity & David et al [12] & Monthly mean turbidity from June - September, 2009 \\
\hline $\begin{array}{l}\text { Dissolved Oxygen (DO) } \\
\text { NPS }\end{array}$ & David et al [12] & Monthly mean DO from June - September, 2009 \\
\hline $\begin{array}{l}\text { Total Dissolved Solids } \\
\text { (TDS) }\end{array}$ & David et al [12] & Monthly mean TDS from June - September, 2009 \\
\hline Ammonia, NPS & David et al [12] & Monthly mean Ammonia from June - September, 2009 \\
\hline Phosphate, NPS & David et al [12] & Monthly mean pH from June - September, 2009 \\
\hline Wind & Medugu and Markus, [16] & Average wind speed \\
\hline Solar Radiation & Medugu and Yakubu, [17] & Mean monthly global solar radiation \\
\hline Initial Conditions & David et al $[12]$ & Observed data and professional judgement \\
\hline Plants & $\begin{array}{l}\text { AQUATOX default seed } \\
\text { values }\end{array}$ & Standard seed values for streams \\
\hline Catfish & AQUATOX database & Initial loadings \\
\hline
\end{tabular}

Initial water quality parameters from David et al. [12] were used to simulate the AQUTOX model. Through model simulation, the water quality parameter such as dissolved oxygen, temperature, ammonia, total Phosphorous and interaction with some aquatic species were monitored. The model predicted results were compared with the field results of David et al [12]. Graphical comparison of model predicted and observed major water quality parameters, were performed by superposing of observed field result on the model simulated result. The graphical results are shown in Figure 1 t.o Figure 7.

\section{RESULTS AND DISCUSSION}

The observed result matches the predicted output up to the extent of the observed as shown in Figure 1a and Figure 1b. and also gave an insight into the behaviour of oxygen, ammonia, total $\mathrm{P}, \mathrm{pH}$ and Temperature for the remaining period of the year. The oxygen concentration of the stream was observed to increase with time, with a reduction in ammonia concentration. 


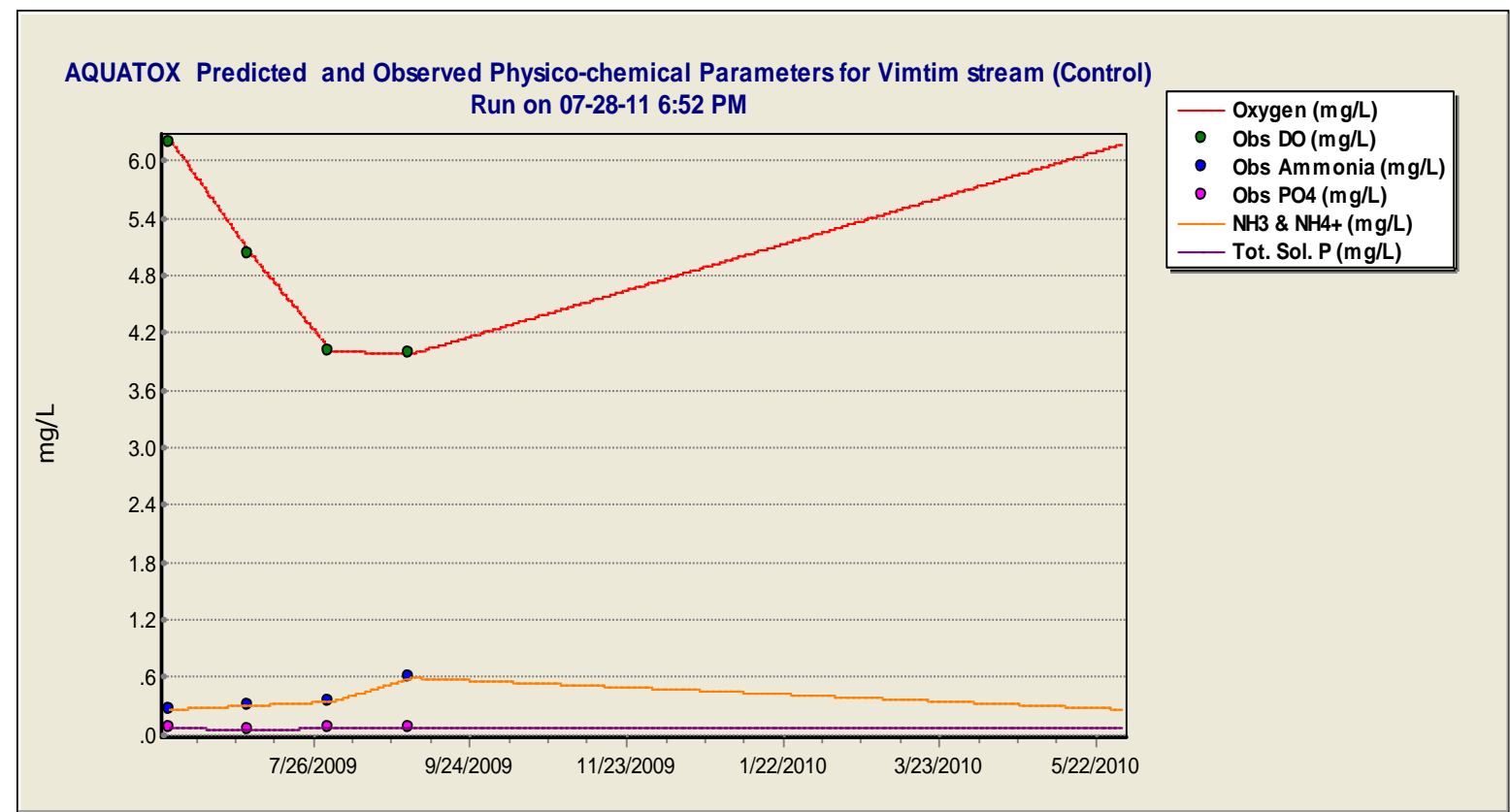

Figure. 1a: Comparison of AQUATOX model prediction and observed data for dissolved oxygen, ammonia and phosphate.

The default information for plants in AQUATOX was used to simulate some selected plants in Vimtim stream and the predicted outputs are as shown in Figure 2. The simulated plant reduced from its initial conditions for a certain period and remained constant for the remaining period of simulation. The simulated aquatic species; catfish and mayfly as represented in Figure 3 showed a reduction in catfish number over the simulated period. This implies survival of the catfish as reported by David et al, [12] but the predicted reduction in number showed the possible effect of continual pollution on the stream biota with time. The fates of some of the water quality parameters are shown in Figure 4 are within water quality standards acceptable range. However, the reported water quality parameters may alter as pollution continues over the years. Figure 5 and Figure 6 showed the fate of chlorophyll a and status of sediments (detritus) in the stream as predicted by the model. Figure 7 agreed with David et al 2010 suggestion of no or negligible catfish mortality due to water quality parameters, the model predicted catfish mortality was from other unknown causes. This suggests the possibility of other contaminant.

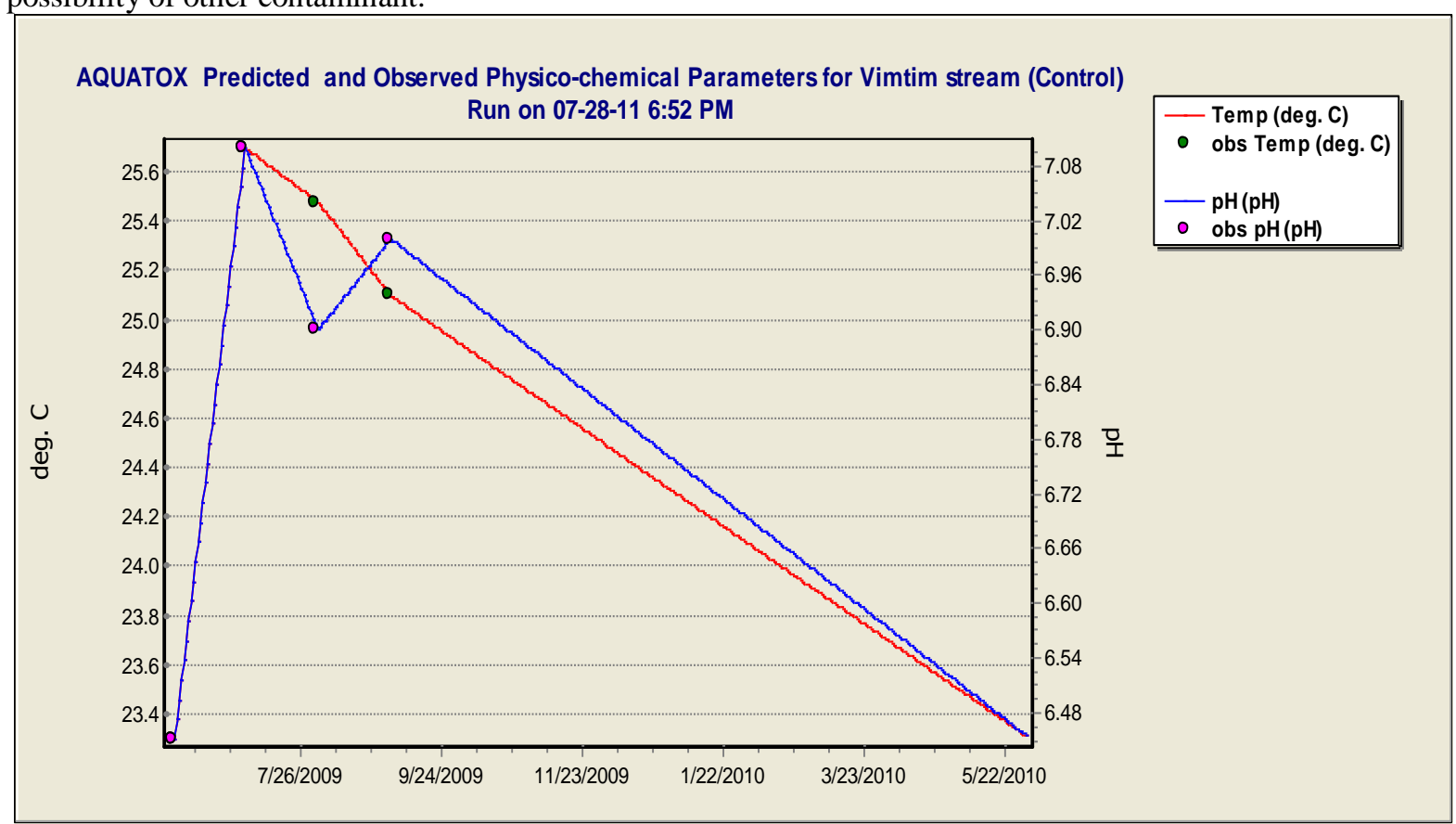

Fig. 1b: AQUATOX comparing observed data with predicted data for $\mathrm{pH}$ and Temperature 


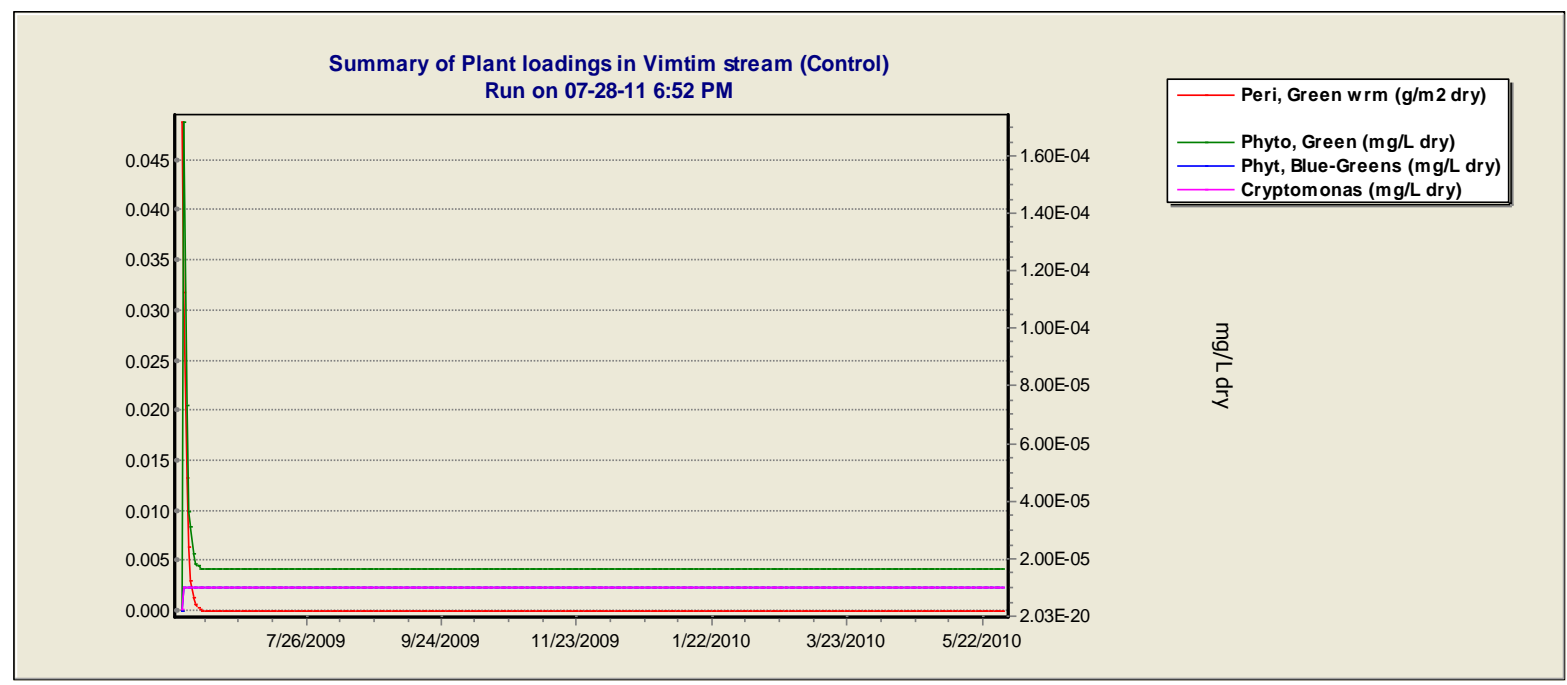

Fig. 2: Summary of Plants simulated for Vimtim stream

Fate of Animals modelled in Vimtim stream (Control) Run on 07-28-11 6:52 PM

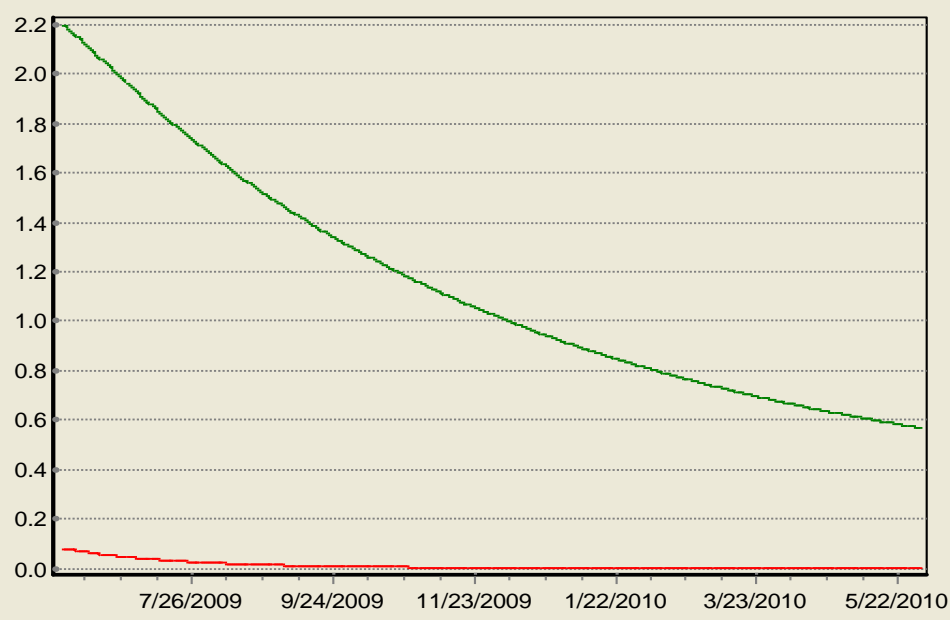

Fig. 3: Aquatic species as modeled with AQUATOX for Vimtim stream

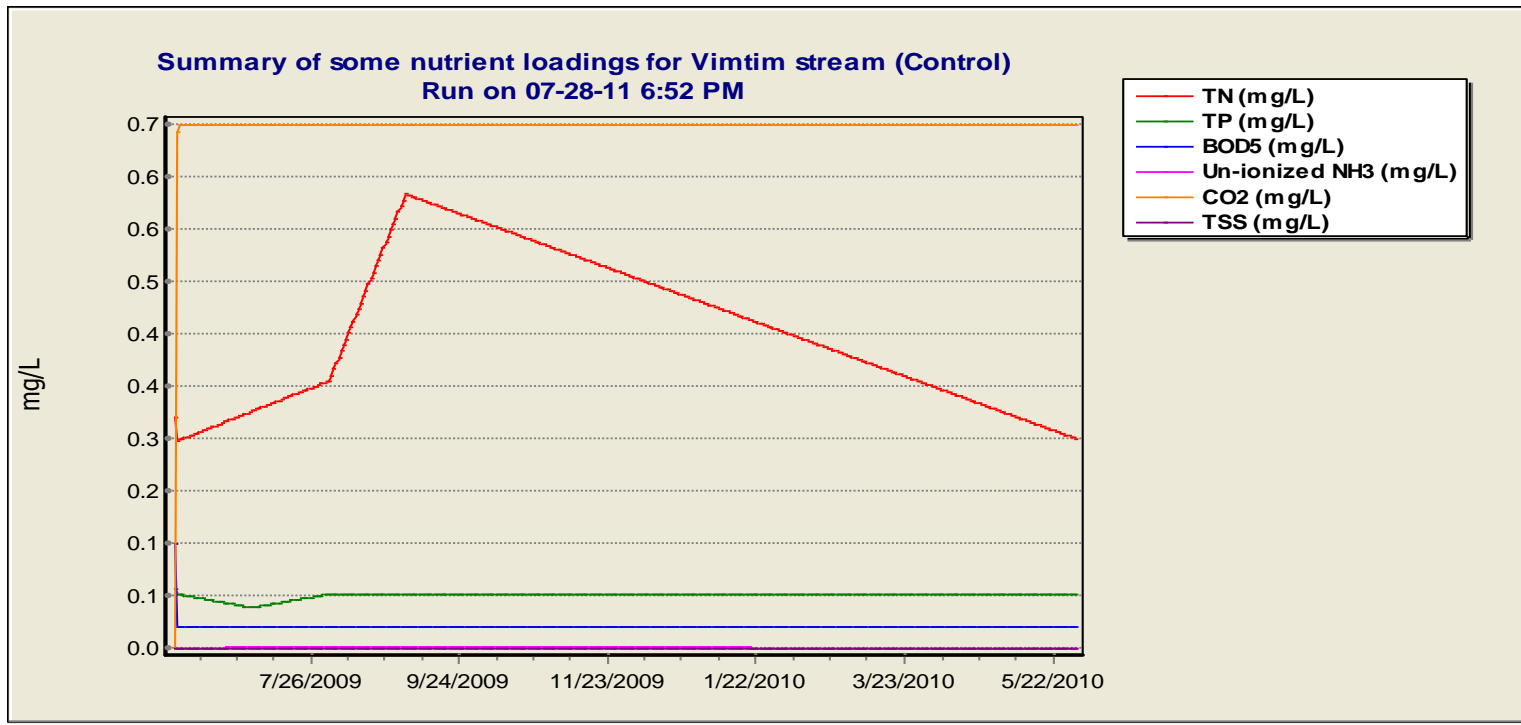

Fig. 4: Total N, P and some nutrients loadings modeled for Vimtim stream 


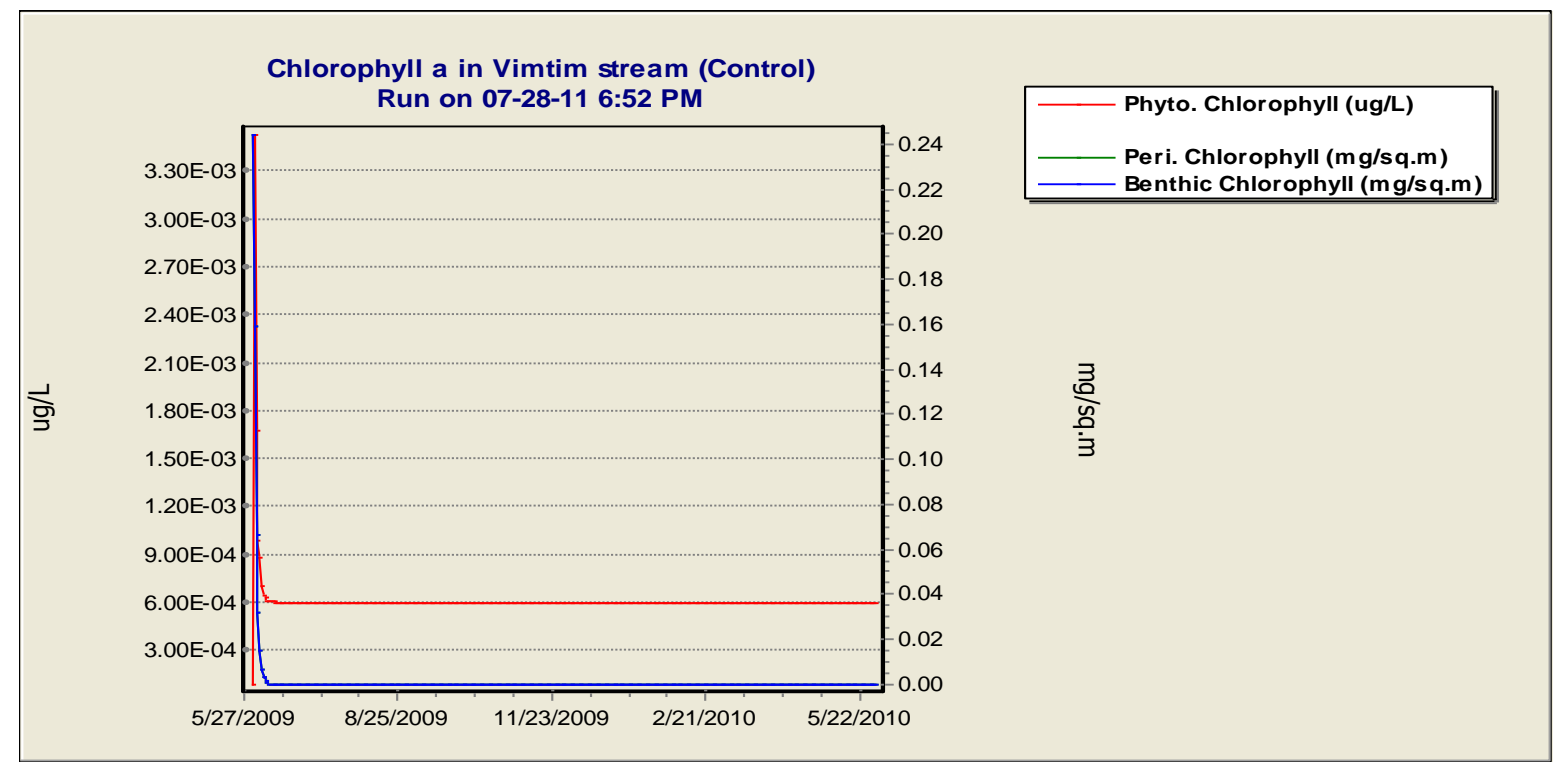

Fig. 5: Chlorophyll a as predicted for Vimtim stream using the AQUATOX model

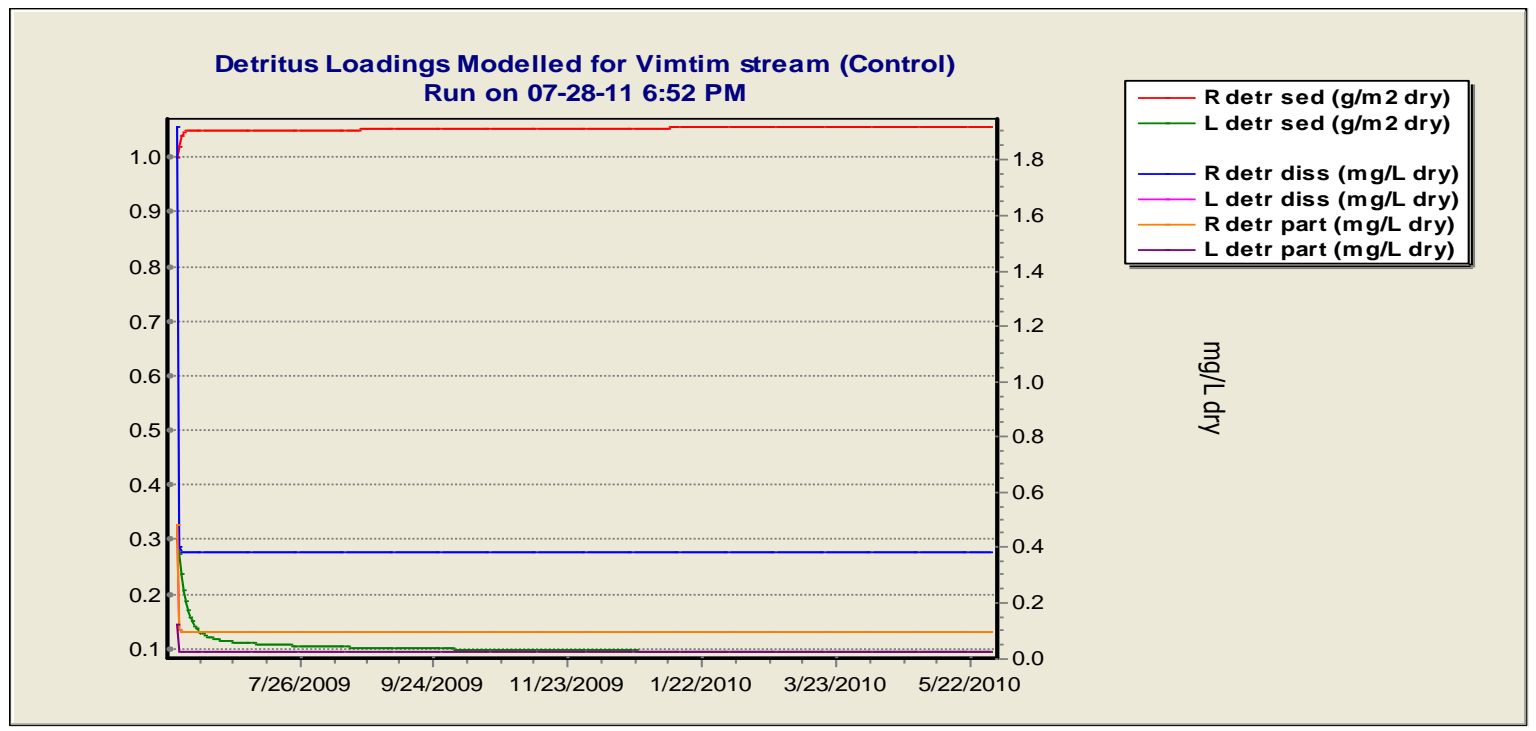

Fig. 6: Detritus (refractory and labile) in Vimtim stream

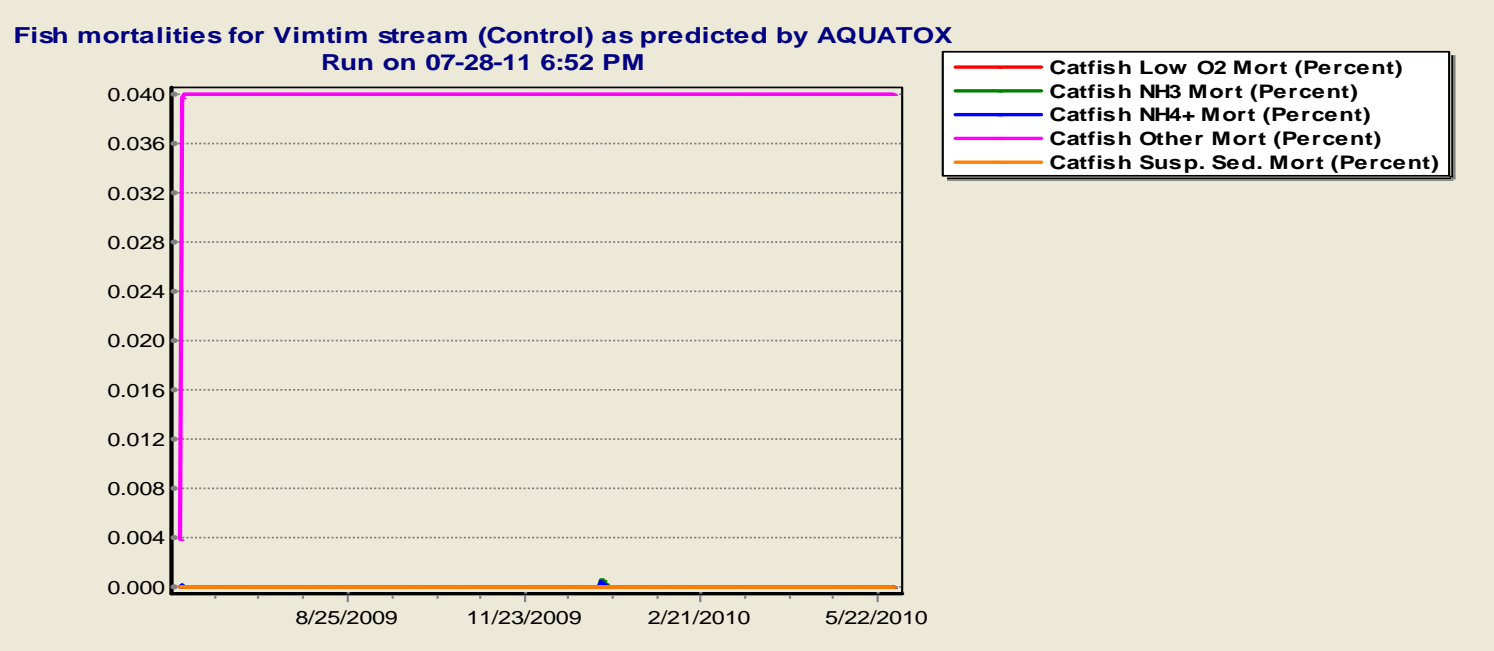

Fig. 7: Catfish mortalities in Vimtim Stream as predicted by AQUATOX 


\section{CONCLUSION}

The AQUATOX model could predict the nutrient time-dependent concentrations in Vimtim stream over a long period of time and use them to identify the key processes that affected water quality parameter and the biotic organisms. The biomass changes for catfish and mayfly which were not adequately accounted for using the conventional methods of measurement could be predicted. The model presented here could be a useful tool to assess evolution trends rather than accurate values because of limited model input data and real environmental complexity. It needs to be adequately validated further for real environmental characters, to obtain more reliable prediction results.

\section{REFERENCES}

[1] LEI Bingli, HUANG Shengbiao, QIAO Min, LI Tianyun, WANG Zijian (2008) Prediction of the environmental fate and aquatic ecological impact of nitrobenzene in the Songhua River using the modified AQUATOX model. Journal of Environmental Sciences 20: 769-777

[2] Smith E P, Cairns Jr. J, (1993). Extrapolation methods for setting ecological standards for water quality: Statistical and ecological concerns. Ecotoxicology, 2: 203-219.

[3] Naito W, Miyamoto K, Nakanishi J, Masunaga S, Bartell S M, (2002). Application of an ecosystem model for aquatic ecological risk assessment of chemicals for a Japanese lake. Water Research, 36: 1-14.

[4] He, M. C, Wang Z J, Tang H X, (2001). Modeling the ecological impact of heavy metals on aquatic ecosystems: a framework for the development of an ecological model. The Science of Total Environment, 266: $291-298$.

[5] Ang M L, Peers K, Kersting E, Fassmann W, Tuomisto H, Lundstrom P, Helle M, Gustavsson V, Jacobsson P, 2001. The development and demonstration of integrated models for the evaluation of severe accident management strategies- SAMEM. Nuclear Engineering and Design, 209(1-3): 223-231.

[6] Bartell, S.M, Lefebvre, G., Kaminski, G., Kaminski, G., Carreau, M., Campbell, K.R., (1999). An ecosystem model for assessing ecological risks in Que0bec rivers, lakes, and reservoirs. Ecological Modeling, 124: 43-67.

[7] Ray S, Berec L, Stra`skraba M, Jørgensen S E, (2001). Optimization of exergy and implications of body sizes of phytoplankton and zooplankton in an aquatic ecosystem model. Ecological Modelling, 140(3): 219-234.

[8] Kumblad L, Gilek M, Næslund B, Kautsky U, (2003). An ecosystem model of the environmental transport and fate of carbon-14 in a bay of the Baltic Sea, Sweden. Ecological Modelling, 166(3): 193210.

[9] Chow T E, Gaines K F, Hodgson, M.E., Wilson, M.D., (2005). Habitat and exposure modelling for ecological risk assessment: A case study for the raccoon on the Savannah River Site. Ecological Modelling, 189(1-2): 151-167.

[10] Larocque, G.R, Mauriello, D.A, Park, R.A, Rykiel Jr, E.J., (2006). Ecological models as decision tools in the 21st century: Proceedings of a conference organized by the International Society for Ecological Modelling (ISEM) in QueObec, Canada, August 22-24, 2004. Ecological Modelling, 199(3): 217-218.

[11] Park R A, Clough J S, Wellman M C, (2008). AQUATOX: modeling environmental fate and ecological effects in aquatic ecosystems. Ecological Modeling, 213(1): 1-15.

[12] David, D.L., Edward, A., Addass, P.A. and Jesse, C. (2010). Some Aspects of Water Quality and the Biology of Clarias gariepinus in Vimtim Stream, Mubi Adamawa State, Nigeria. World Journal of Fish and Marine Scineces 2(2): 129-133.

[13] Boyd, E. and F. Lichoktkoper, (1990). Water quality management in fish pond culture. Research and Development Series No. 22. International Centre for Aquacultural Experimentation. Auburn University, Alabama.

[14] Google Earth (2011). “Mubi." Coordinates: $10^{\circ} 16^{\prime} \mathrm{N} 13^{\circ} 16^{\prime} \mathrm{E} / 10.267^{\circ} \mathrm{N} 13.267^{\circ} \mathrm{E}$.

[15] Park, R.A. and Clough, J.S. (2009). AQUATOX (release 3) Modelling Environmental Fate and Ecological Effects in Aquatic Ecosystems Volume 2: Technical Documentation. United States Environmental Protection Agency.Office of Water (4305) EPA-823-R-09-004.

[16] Medugu, D.W. and Markus, A. (2011). Wind as a Viable Source of Energy for Fluctuation of Electric Power in Yola. Ozean Journal of Applied Sciences 4(1): $41-50$.

[17] Medugu, D.W. and Yakubu, D. (2011) Estimation of mean monthly global solar radiation in Yola Nigeria using angstrom model. Advances in Applied Science Research 2 (2): 414-421. 